\section{Synthesis of Large Low-Redundancy Linear Arrays}

Adriano Camps, Angel Cardama, and D. Infantes

\begin{abstract}
Aperture synthesis interferometric radiometers can overcome mass, weight and mechanical scan limitations of present-day radiometers. A full antenna array is "thinned" by eliminating selected antennas, while keeping all possible antenna separations. This brief describes a new technique for the direct synthesis of low-redundancy large arrays, consisting in growing small arrays by inserting a seed repeatedly. This technique has achieved the largest thinned arrays with the least redundancy reported in the literature.
\end{abstract}

Index Terms-Aperture synthesis radiometers, baseline, interferometric radiometers, redundancy, thinned arrays.

\section{INTRODUCTION}

The basic measurement of a one-dimensional synthetic aperture interferometric radiometer is the complex cross correlation $V(u)$ of the signals collected by two antennas (1 and 2) at different positions $\left(x_{1}\right.$ and $\left.x_{2}\right), u$ is given by $u=\left(x_{2}-x_{1}\right) / \lambda$, and $\lambda$ is the electromagnetic wavelength. In a full array of $N$ antennas equally spaced $u_{0}$ wavelengths $V(u)$ can be measured $N$ times at $u=0, N-1$ times at $u=1 \cdot u_{0}, N-2$ times at $u=2 \cdot u_{0}, \ldots$ and only once at $u_{\max }=(N-1) \cdot u_{0}$. This is an inefficient use of the available antennas, since most of the measurements are redundant. In 1955, Arsac [1] found that the greater efficiency can be achieved by spacing the $N$ antennas out in such a way that the greatest multiple of $u_{0}, u_{\max }=N_{\max } u_{0}$, is greater than $(N-1) u_{0}$ and all multiples up to $u_{\max }$ are also present. The "restricted" minimum-redundancy problem is to find, for a given $N$, a spacing pattern of this kind that has maximum efficiency (minimum redundancy). The "general" problem allows $N_{\max }$ to be greater than the number $M$ for which all multiples of $u_{0}$ up to $M \cdot u_{0}$ are present. In this brief we consider only the restricted problem.

Redundancy $R$ is quantitatively defined as the number of pairs of antennas divided by $N_{\max }: R=(1 / 2) N(N-1) / N_{\max }$ [2]. For $N \leq 4$ Arsac [1] found arrays with $R=1$ ("zero-redundancy" linear arrays; ZRLAs), and Bracewell [3] proved that these are the only ZRLAs. In 1956, Leech [4] provided some optimum solutions for $N \leq 11$, and demonstrated that $1.217 \leq R \leq 1.332$ for $N \rightarrow \infty$. Although the solutions provided for $N \leq 11$ were not zero-redundant, the redundancy was the lowest possible ( $R=R_{\text {opt }}>1$ : minimum redundancy linear arrays, MRLA). For larger values of $N>11$, the optimum solutions have not been found, but some semi-empirical and numerical array patterns that approach Leech's bounds (low redundancy linear arrays, LRLA) have been found [4]-[8]

The nomenclature used to denote an array of $N$ antennas is a bracketed list of $N-1$ numbers $\{x, y, \ldots z\}$ indicating the spacing between adjacent antennas. For example, the ZRLA $\{1,3,2\}$ (Table I) is a four-antenna array that looks like xxooxox where crosses indicate positions occupied by an antenna, and circles void positions.

\section{SYNTHESIS OF LOW-REDUNDANCY ARRAYS}

This brief describes how, by searching a pattern in their growth, long LRLAs can be generated from smaller ones. First, when all MRLA

Manuscript received December 17, 1998; revised February 27, 2001.

The authors are with the Department of Signal Theory and Communications, Universitat Politècnica de Catalunya, 08034 Barcelona, Spain (e-mail camps@tsc.upc.es; cardama@tsc.upc.es).

Publisher Item Identifier S 0018-926X(02)10629-6. configurations from $N=1$ to 11 are tabulated (Table I), two patterns are found.

1) Every new configuration is constructed by inserting an antenna in the center of the array which is spaced from adjacent elements a distance equal to the maximum spacing in the array (maximum number in the list). For example, a family of MRLAs is generated from the array $\{1,1,4,3\}$ by inserting antennas at the center spaced $4 \cdot u_{0}:\{1,1, \underline{4}, 3\} \rightarrow\{1,1, \underline{4}, \underline{4}, 3\} \rightarrow$ $\{1,1, \underline{4}, \underline{4}, \underline{4}, 3\} \rightarrow\{1,1, \underline{4}, \underline{4}, \underline{4}, \underline{4}, 3\}$. In this way, a set of optimum MRLAs is generated up to the $N / N_{\max }=8 / 21$ configuration, which is a LRLA $\left(N / N_{\max }=8 / 23\right.$ for a MRLA, Table I).

2) Every new configuration is generated by inserting an antenna at the end of the array spaced the same length as the most frequent one. Moreover, the separation between the most distant adjacent antennas is increased by the same amount. For example, a family is generated as follows $\{1,5,3,2,2\} \rightarrow\{1, \underline{\mathbf{7}}, 3,2,2, \underline{\mathbf{2}}\}$, where $7=5+2$ and 2 has been added at the end of the configuration.

Starting with MRLAs, the sequence of optimum LRLAs that can be generated finishes at 12/50. For $N=13, N_{\max }=57$ instead of the maximum reported value (58). Larger LRLAs can be generated from parent arrays with a higher redundancy as described below.

1) The parent array is split into two. When $N$ is odd, the number of elements in the list is even and it is split at the center. When $N$ is even, the list can be split either at the $(N-1) / 2$ or at the $N / 2$ position.

2) Every new array in the sequence is constructed by repeatedly inserting a number at the position where the list has been split. This number is equal to the number of antennas $(N)$ in the parent configuration.

In order to ensure that the array is restricted, the number inserted in the center of the list must appear at least twice. For example, the array configuration $13 / 58$ can be generated from the $9 / 22$ following the sequence $\{1,1,4,2,3,7,3,1\} \rightarrow \cdots \rightarrow$ $\{1,1,4,2, \underline{\mathbf{9}}, \underline{\mathbf{9}}, \underline{\mathbf{9}}, \underline{\mathbf{9}}, 3,7,3,1\}$ or $\{1,4,3,4,5,1,2,2\} \rightarrow \cdots \rightarrow$ $\{1,4,3,4, \underline{\mathbf{9}}, \underline{\mathbf{9}}, \underline{\mathbf{9}}, \underline{\mathbf{9}}, 5,1,2,2\}$, and all the intermediate arrays $9 / 22$, $10 / 31,11 / 40,12 / 49$ are also restricted.

Table I summarizes the main results. The first part reproduces Arsac's ZRLAs up to 4 antennas. The second part of the table reproduces some of Leech's optimum MRLAs up to 11 antennas. The third part presents the results up to the 30/293 configuration obtained with the method described in this brief. Array configurations and redundancies are compared to the ones with the lowest redundancy reported to date [6]. New array configurations that improve the existing ones are marked with a star $(\star)$. Finally, the fourth part of the table presents new larger thinned LRLAs, generated from the 30/287 and $30 / 293$ parent arrays by repeatedly inserting $19 \mathrm{~s}$ and $17 \mathrm{~s}$ at the center of the array configuration lists.

\section{CONCLUSION}

This brief presents a technique to make known small LRLA grow into very large LRLA. The main advantages of this technique are direct synthesis of very large thinned arrays with very low computation time and the lowest degree of redundancy reported to date. These configurations can be used to define the array structure of new high resolution synthetic aperture interferometric radiometers. The regularity of the pattern at the central part of the arrays will facilitate the construction of space deployable structures. 
TABLE I

COMPARISON OF EXISTING ZRLA, MRLA, AND LRLA With THE NEW LRLA ObTAINED By the Proposed Method. Symbols $N$ : Number of ANTENNAS, $N_{\text {max }}$ : MAXIMUM ARRAY SpaCING, $R$ : REDUNDANCY

\begin{tabular}{|c|c|c|c|c|}
\hline$N$ & $N_{\max }$ & Pattern & $\boldsymbol{R}$ & Comments (array family) \\
\hline I & 0 & $\{0\}$ & 1.00 & ZRLA [I] \\
\hline 2 & $\mathbf{I}$ & $\{1\}$ & 1.00 & IRLA [1] \\
\hline 3 & 3 & $\{1,2\}$ & 1.00 & ZRLA []] (A) \\
\hline 4 & 6 & $\{1,3,2\}$ & 1.00 & ZRLA [I] (A) \\
\hline 5 & 9 & $\begin{array}{l}\{1,3,3,2\} \\
\{1,1,1,4\}\end{array}$ & I.II & $\begin{array}{l}\operatorname{MRLA}[1,3](A) \\
\text { (B) }\end{array}$ \\
\hline 6 & B3 & $\begin{array}{l}\{1,1,4,4,4,3\} \\
\{1,5,3,2,2\} \\
\{1,3,1,6,2\}\end{array}$ & 1.15 & $\begin{array}{l}\text { MRLA }[1,3](B) \\
\left(C_{1}\right)\end{array}$ \\
\hline 7 & 17 & $\begin{array}{l}\{1,1,4,4,4,4,3\} \\
\{1,7,3,2,2,2\} \\
\{1,3,3,2,2,3,2\} \\
\{1,1,6,4,2,3\} \\
\{1,1,1,6,4,3,2\} \\
\{1,1,1,5,5,4\}\end{array}$ & 1.24 & $\begin{array}{l}\text { MRLA [I,3] (B) } \\
\left(C_{1}\right) \\
(D)\end{array}$ \\
\hline 8 & 23 & $\begin{array}{l}\{1,1,9,4,3,3,2\} \\
\{1,3,6,6,2,3,2\}\end{array}$ & 1.22 & $\begin{array}{l}\operatorname{MRLA}[1,3]\left(\mathrm{C}_{2}\right) \\
\text { (D) }\end{array}$ \\
\hline 9 & 29 & $\begin{array}{l}\{1,2,3,7,7,4,4,4,1\} \\
\{1,1,12,4,3,3,3,2\} \\
\{1,3,6,6,6,2,3,2\}\end{array}$ & 1.24 & $\begin{array}{l}\text { MRLA [I,3] (E) } \\
\left(C_{2}\right) \\
(D)\end{array}$ \\
\hline 10 & 36 & $\{1,2,3,7,7,7,4,4,1\}$ & 1.25 & MRLA $[I, 3](E)$ \\
\hline II & 43 & $\{1,2,3,7,7,7,7,4,4,1\}$ & 1.28 & $\operatorname{MRLA}[1,3](E)$ \\
\hline 12 & 50 & $\begin{array}{l}\{1,2,3,7,7,7,7,7,7,4,4,1\} \\
\{1,1,1,20,5,4,4,4,4,3,3\}\end{array}$ & 1.32 & $\begin{array}{l}\text { LRLA [6] } \\
\text { New LRLA }\end{array}$ \\
\hline B & 58 & $\begin{array}{l}\{1,2,3,11,3,7,8,10,4,4,4,1\} \\
\{1,1,1,24,5,4,4,4,4,4,4,3,3\} \\
\{1,4,3,4,9,9,9,9,5,1,2,2\} \\
\{1,3,7,3,9,9,9,9,2,4,1,1\} \\
\{1,1,6,7,1,10,10,10,1,4,2,3\}\end{array}$ & 1.34 & $\begin{array}{l}\text { LRLA [6] } \\
\text { New LRLA } \\
\text { New LRLA } \\
\text { New LRLA } \\
\text { New LRLA }\end{array}$ \\
\hline 14 & 68 & $\begin{array}{l}\{1,1,1,6,6,6,11,11,11,5,5,3,1,1,1\} \\
\{1,1,6,7,1,10,10,10,10,3,4,2,3\}\end{array}$ & 1.34 & $\begin{array}{l}\text { LRLA [6] } \\
\text { New LRLA }\end{array}$ \\
\hline 15 & 79 & $\{1,1,6,6,6,6,11,11,11,11,5,5,3,1,1,1\}$ & 1.33 & LRLA [6] \\
\hline 16 & 90 & 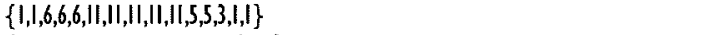 & 1.33 & LRLA [6] \\
\hline 17 & 101 & $\{1,1,6,6,6,6, I I, I I, I I, I I, I I, I I, 5,5,3,1,1, I\}$ & 1.35 & LRLA [6] \\
\hline 18 & II2 & $\{1,1,6,6,6,6, I, I I, I I, I I, I I, I I, I I, 5,5,3,1,1\}$ & 1.37 & LRLA [6] \\
\hline \multirow[t]{2}{*}{19} & 121 & $\{1,1,1,1,1,4,45,8,7,6,6,6,6,6,6,6,6,5,5,4\}$ & 1.41 & LRLA [6] \\
\hline & 123 & $\{1,1,6,6,6,6,11,11,11,11,11,11,11,11,5,5,3,1,11\}$ & 139 & New LRLA $\star *$ \\
\hline \multirow[t]{2}{*}{20} & 133 & $\{1,1,1,2,5,7,7,1,13,13,13,13,13,13,13,6,6,4,1,1,1\}$ & 1.43 & LRLA [6] \\
\hline & 134 & $\{1, I, 6,6,6,6,11,11,11,11, I 1, I I, I I, I I, I 1,5,5,3,1,1\}$ & 1.42 & New LRLA \\
\hline 21 & 145 & $\begin{array}{l}\{1,1,1,1,1,1,1,53,9,6,5,8,7,7,7,7,7,7,4,6,6,6\} \\
\{1,2,1,1,1,1,5,5,14,14,14,14,14,14,14,9,4,9,3,1\}\end{array}$ & 1.45 & $\begin{array}{l}\text { LRLA [6] } \\
\text { New LRLA }\end{array}$ \\
\hline \multirow[t]{2}{*}{22} & 160 & $\{1,2,6,6,8,1,13,13,8,5,13,13,13,13,13,13,5,2,5,4,3\}$ & 1.44 & LRLA [6] $\left.{ }^{*}\right)$ \\
\hline & 159 & $\begin{array}{l}\{1,2,1,1,1,1,5,5,5,14,14,14,14,14,14,14,14,9,4,9,3,1\} \\
\{1,1,1,1,1,1,60,9,6,5,8,7,7,7,7,7,7,7,4,6,6\}\end{array}$ & 1.45 & $\begin{array}{l}\text { New LRLA } \$ \\
\text { New LRLA } \$\end{array}$ \\
\hline 23 & 173 & $\{1,2,1,1,1,1,5,5,5,14,14,14,14,14,14,14,14,14,9,4,9,3,1\}$ & 1.46 & LRLA [6] \\
\hline \multirow[t]{2}{*}{24} & 188 & $\{1,2,3,1,1,1,5,2,5,7,1,16,16,16,16,16,16,16,16,9,9,4,7,7,2,2\}$ & 1.47 & LRLA [6] \\
\hline & 191 & $\{1,1,1,1,8,1,1,9,9,9,17,17,17,17,17,17,17,8,8,8,5,1,1,1\}$ & 1.45 & New LRLA $\star$. \\
\hline 25 & 208 & $\{1,1,1,1,1,8,1,9,9,9,17,17,17,17,17,17,17,17,8,8,8,8,5,1,1,1\}$ & 1.44 & LRLA [6] \\
\hline 26 & 225 & $\{1,1,1,2,3,3,8,8,8,17,17,17,17,17,17,17,17,17,9,9,1,9,9,1,1,1\}$ & 1.44 & LRLA [6] \\
\hline \multirow[t]{2}{*}{27} & 236 & $\{1,1,2,6,3,6,6,16,16,16,16,16,16,16,16,16,16,16,10,3,4,3,7,3,4,1\}$ & 1.49 & LRLA [6] \\
\hline & 242 & $\{1,1,1,2,3,8,8,8,8,17,17,17,17,17,17,17,17,17,17,9,9,1,9,9,1,1,1\}$ & $\mathrm{I} .45$ & New LRLA \\
\hline \multirow[t]{2}{*}{28} & 257 & $\{1,1,1,5,8,7,1,7,17,17,17,17,17,17,17,17,17,17,17,9,9,9,6,3,1,1,1\}$ & 1.47 & LRLA [6] \\
\hline & 259 & $\{1,1,1,1,2,3,8,8,8,8,17,17,17,17,17,17,17,17,17,17,17,9,9,1,1,9,9,1,1,1\}$ & 1.46 & New LRLA D \\
\hline \multirow[t]{2}{*}{29} & 270 & $\{1,1,3,2,2,220,2,1,19,19,19,19,19,19,19,19,19,19,16,1,4,3,9,1,3,8,2,2,1\}$ & 1.50 & LRLA [6] \\
\hline & 276 & $\{1,1,1,2,3,8,8,8,8,17,17,17,17,17,17,17,17,17,17,17,17,9,9,1,9,9,1,1,1,1\}$ & 1.47 & New LRLA $\mathbb{K}_{k}$ \\
\hline \multirow[t]{2}{*}{30} & 287 & $\{1,1,12,2,6,6,8,6,6,19,19,19,19,19,19,19,19,19,19,19,11,2,5,6,3,2,2,2,1,1,1\}$ & 1.52 & LRLA [6] \\
\hline & 293 & $\{1,1,1,2,2,3,8,8,8,8,17,17,17,17,17,17,17,17,17,17,17,17,17,9,9,1,9,9,1,1,1,1\}$ & 1.48 & New LRLA \\
\hline \multirow[t]{2}{*}{31} & 306 & $\{1,1,112,2,6,6,8,6,6,19,19,19,19,19,19,19,19,19,19,19,19,11,2,5,6,3,2,2,3,1,1,1\}$ & 1.52 & New LRLA \\
\hline & 310 & $\{1,1,1,2,2,3,8,8,8,17,17,17,17,17,17,17,17,17,17,17,17,17,17,17,9,9,1,19,9,1,1,1,1\}$ & 1.50 & New LRLA $\star *$ \\
\hline \multirow[t]{2}{*}{32} & 325 & $\{1,1,12,2,6,6,6,8,6,19,19,19,19,19,19,19,19,19,19,19,19,19,11,2,5,6,3,2,2,2,3,1,1\}$ & 1.53 & New LRLA \\
\hline & 327 & $\{1,1,1,2,3,8,8,8,8,17,17,17,17,17,17,17,17,17,17,17,17,17,17,17,9,9,1,9,9,1,1,1\}$ & 1.52 & New LRLA ל \\
\hline \multirow[t]{2}{*}{33} & 344 & $\{1,1,12,2,6,6,6,8,6,19,19,19,19,19,19,19,19,19,19,19,19,19,19,11,2,5,6,6,3,2,2,3,1,1\}$ & 1.53 & New LRLA $\underset{K}{*}$ \\
\hline & 344 & $\{1,1,1,1,2,3,8,8,8,17,17,17,17,17,17,17,17,17,17,17,17,17,17,17,17,9,9,1,9,9,9,1,1,1\}$ & 1.53 & New LRLA $\$$ \\
\hline 34 & 363 & $\{1,1,12,2,6,6,8,6,19,19,19,19,19,19,19,19,19,19,19,19,19,19,19,11,2,5,6,3,2,2,3,1,1\}$ & 1.55 & New LRLA $\$ \\
\hline & 361 & $\{1,1,1,1,2,3,8,8,8,17,17,17,17,17,17,17,17,17,17,17,17,17,17,17,17,17,9,9,1,9,9,1,1,1\}$ & 1.55 & New LRLA \\
\hline 35 & 382 & $\{1,1,12,2,6,6,6,8,6,19,19,19,19,19,19,19,19,19,19,19,19,19,19,19,19,11,2,5,6,6,3,2,2,3,1,1\}$ & 1.56 & New LRLA $\$$ \\
\hline & 378 & $\{1,1,1,2,3,8,8,8,17,17,17,17,17,17,17,17,17,17,17,17,17,17,17,17,17,17,9,9,1,9,9,1,1,1\}$ & 1.57 & New LRLA \\
\hline 36 & 401 & $\{1,1,12,2,6,6,8,6,6,19,19,19,19,19,19,19,19,19,19,19,19,19,19,19,19,19,11,2,5,6,3,2,2,3,1,1\}$ & 1.57 & New LRLA \\
\hline & 395 & $\{1,1,1,2,2,8,8,8,8,17,17,17,17,17,17,17,17,17,17,17,17,17,17,17,17,17,17,17,9,9,1,9,9,1,1,1,1\}$ & 1.59 & New LRLA \\
\hline 37 & 420 & $\{1,1,12,2,6,6,6,8,6,19,19,19,19,19,19,19,19,19,19,19,19,19,19,19,19,19,19,11,2,5,6,3,2,2,3,3,1,1\}$ & 1.59 & New LRLA $\$$ \\
\hline & 412 & $\{1,1,1,2,3,8,8,8,8,17,17,17,17,17,17,17,17,17,17,17,17,17,17,17,17,17,17,17,17,9,9,1,9,9,1,1,1,1\}$ & 1.62 & New LRLA \\
\hline
\end{tabular}

$\left({ }^{*}\right)$ There is a typographic error in [6], since there are 12 antenna spacings missing in the pattern given for $N=22, N_{\max }=160$.

New and largest LRLAs with the least redundancies reported up to date. 


\section{REFERENCES}

[1] J. Arsac, "Nouveau réseau pour l'observation radio astronomique de la brillance sur le soleil à 9359 MC," Compte Rend. Acad. Sci., vol. 240, pp. 942-945, 1955.

[2] A. T. Moffet, "Minimum-redundancy linear arrays," IEEE Trans. Antennas Propagat., vol. AP-16, pp. 172-175, 1968.

[3] R. N. Bracewell, "Optimum spacings for radio telescopes with unfilled apertures," Natl. Acad. Sci. Natl. Res. Council. Publ., vol. 1408, pp. 243-244, 1966.
[4] J. Leech, "On the representation of $1,2, \ldots, n$ by differences," $J$ London Math. Soc., vol. 31, pp. 160-169, 1956.

[5] M. Ishiguro, "Minimum redundancy linear arrays for a large number of antennas," Radio Sci., vol. 15, no. 6, pp. 1163-1170, 1980.

[6] C. S. Ruf, "Numerical annealing of low-redundancy linear arrays," IEEE Trans. Antennas Propagat., vol. 42, pp. 85-90, 1993.

[7] A. Trucco, E. Omodei, and P. Repetto, "Synthesis of sparse planar arrays," Electron. Lett., vol. 33, no. 22, pp. 1834-1835, October 1997.

[8] M. J. Rossouw, J. Joubert, and D. A. McNamara, "Thinned arrays using a modified minimum redundancy synthesis technique," Electron. Lett., vol. 33, no. 10, pp. 826-827, May 1997. 